\title{
Die Bundesdatenschutzaufsicht auf dem Weg zur politischen Unabhängigkeit
}

Am 17.12.2014 hat der Innenausschuss des Deutschen Bundestages den Weg frei gemacht für die von der Regierungskoalition geplante „Stärkung der Unabhängigkeit der Datenschutzaufsicht im Bund“. Gegen die Stimmen der Oppositionsfraktionen Die Linke und Bündnis 90/Die Grünen verabschiedete das Gremium einen entsprechenden Gesetzentwurf der Bundesregierung ${ }^{1}$ in modifizierter Fassung. Die Vorlage stand am 18.12.2014 zur abschließenden Beratung auf der Tagesordnung des Bundestagsplenums. Danach soll das Amt der Bundesbeauftragten für den Datenschutz und die Informationsfreiheit den rechtlichen Status einer obersten Bundesbehörde erhalten, die eigenständig und unabhängig ausgestaltet ist.

Derzeit untersteht die Bundesbeauftrage(BfDI) der Dienstaufsicht des Bundesinnenministeriums (BMI), während die Rechtsaufsicht durch die Bundesregierung ausgeübt wird. In der Praxis finde keine Dienst- oder Rechtsaufsicht statt und die Unabhängigkeit werde nicht eingeschränkt, schreibt die Regierung in der Vorlage. Der Wortlaut des Bundesdatenschutzgesetzes entspricht ihren Angaben zufolge jedoch im Wesentlichen den bisherigen Vorschriften für die Kontrollstellen der Länder, die nach Einschätzung des Europäischen Gerichtshofs mit europarechtlichen Vorschriften nicht vereinbar sind. Insbesondere in Urteilen vom 9. März 2010 und 16. Oktober 2012 habe der EuGH die Anforderungen an die Unabhängigkeit der datenschutzrechtlichen Kontrollstellen präzisiert. Mit dem Gesetzentwurf solle „diesen Anforderungen Genüge getan“" und zugleich die Datenschutzaufsicht auf Bundesebene insgesamt gestärkt werden.

Danach soll die Bundesbeauftragte mit Dienstsitz in Bonn künftig ausschließlich parlamentarischer und gerichtlicher Kontrolle unterstehen. Auf eine Rechtsaufsicht der Bundesregierung und Dienstaufsicht des BMI soll verzichtet und die organisatorische Anbindung an das Ministerium aufgehoben werden. Gewählt werden soll die Bundesbeauftrage laut Vorlage vom Bundestag; ihren Amtseid soll sie vor dem Bundespräsidenten leisten.

Mit den Stimmen der Unions- und der SPD-Fraktion stimmte der Innenausschuss für einen Änderungsantrag der Koalition. Er sieht vor, dass die Beauftragte als Zeugin aussagen darf, sofern die Aussage nicht Grundrechte verletzen oder „dem Wohle des Bundes oder eines deutschen Landes Nachteile bereiten“" würde, „insbesondere Nachteile für die Sicherheit der Bundesrepublik Deutschland oder ihre Beziehungen zu anderen Staaten“. Auch soll sie nur „im Benehmen“ mit der Bundesregierung aussagen dürfen, wenn die Aussage „laufende oder abgeschlossene Vorgänge“ betrifft, „, die dem Kernbereich exekutiver Eigenverantwortung der Bundesregierung zuzurechnen sind oder sein könnten“. Nach dem Regierungsentwurf hätte eine Aussage in einem solchen Fall „nur im Einvernehmen mit der Bundesregierung“ erfolgen dürfen.

Die CDU/CSU-Fraktion betonte in der Ausschusssitzung, dass die Bundesbeauftragte damit letzten Endes selbst entscheiden könne, ob sie aussagt. Damit werde ihre Stellung noch unabhängiger gestaltet. Mit dem Gesetzentwurf, der am 1. Januar 2016 in Kraft treten soll, sind sechs zusätzliche Stellen bei der Beauftragten vorgesehen.

Die SPD-Fraktion bewertete die Aufstockung um sechs Stellen als einen ersten Schritt. Der Gesetzgeber müsse beim Etat 2016 entscheiden, welche personelle Ausstattung die Bundesbeauftragte zur Erfüllung ihrer Aufgabe brauche.

Die Fraktion Die Linke sprach sich für Berlin als Dienstsitz der Bundesbeauftragten aus. Sie kritisierte, die Regierungskoalition versuche, EU-Vorgaben umzusetzen und zugleich die Bundesbeauftragte „,in Gänze zu entmachten“.

Die Fraktion Bündnis 90/Die Grünen argumentierte, dass die Herstellung der völligen Unabhängigkeit der Bundesbeauftragten seit vielen Jahren geboten sei.

Die amtierende Bundesbeauftragte Andrea Voßhoff machte deutlich, dass aus ihrer Sicht die formelle Unabhängigkeit ihres Amtes mit dem Gesetzentwurf erreicht werde. Sie warb zugleich dafür, in den Etatberatungen aufzugreifen, dass eine personelle Aufstockung bei der künftigen Behörde notwendig sei. Zugleich unterstrich sie, dass viele Gründe für Bonn als deren Dienstsitz sprächen, das Berliner Verbindungsbüro aber bestehen bleiben werde und ihr die Präsenz beim Bundestag wichtig sei.

Für die Bundesregierung verwies ein BMI-Vertreter ebenfalls auf das Berliner Verbindungsbüro und sprach von einer pragmatischen Lösung der Dienstsitzfrage. Mit Blick auf die vorgesehenen Aussageregelungen hob er zudem hervor, dass die letzte Entscheidung über eine Aussage die Bundesbeauftragte selbst treffe.

1 http://dip21.bundestag.de/dip21/btd/18/028/1802848.pdf 